\title{
Regulation of the Enzymes of the meta-Cleavage Pathway of Pseudomonas putida: The Regulon is Composed of Two Operons
}

\author{
By R. C. BAYLY, G. J. WIGMORE* AND D. I. MCKENZIE \\ Department of Microbiology, Monash University Medical School, \\ Commercial Road, Prahran, 3I8I, Victoria, Australia
}

(Received 4 October 1976; revised 2 December 1976)

SU M MAR Y

In Pseudomonas putida NCIBIOOI 5 the gene determining phenol hydroxylase is in a separate operon from the genes determining catechol 2,3-oxygenase and subsequent enzymes of the meta-cleavage pathway.

In the wild-type strain, non-coordinate induction of phenol hydroxylase and catechol 2,3-oxygenase occurred when catechol, phenol or isomers of cresol were used as inducers. Phenol hydroxylase was repressed to a greater extent than catechol 2,3-oxygenase when induced by phenol in the presence of either benzoate or acetate. In a mutant deficient in catechol 2,3-oxygenase, 3- or 4-methylcatechol repressed formation of phenol hydroxylase but not of enzymes functioning later in the pathway.

Four mutants had an altered regulatory element that resulted in different effects on the expression of phenol hydroxylase and catechol 2,3-oxygenase genes when isomers of cresol were used as inducers.

Repression of enzyme induction by acetate, benzoate or 3- or 4-methylcatechol showed that catechol 2,3-oxygenase and subsequent meta-cleavage pathway genes form part of the same operon. Benzoate or 3- or 4-methylcatechol repressed phenol hydroxylase but none of the other enzymes in the pathway, while acetate coordinately repressed catechol 2,3-oxygenase and subsequent enzymes.

\section{INTRODUCTION}

Species of the genus Pseudomonas exhibit an extensive nutritional versatility in regard to sources of carbon (Stanier, Palleroni \& Doudoroff, 1966) and many of the catabolic sequences for dissimilation of these compounds by various species of the genus have been elucidated (Dagley, 1972). However, the regulation of many of these pathways is still unknown and detailed studies at the genetic level are restricted to three systems, namely the hut, catBC and ami loci (Wheelis, 1975).

The degradative sequence for dissimilation of phenol and the isomers of cresol by Pseudomonas putida NCIBIOOI5 (strain U) has been elucidated from biochemical (Bayly, Dagley \& Gibson, I966; Bayly \& Dagley, I969; Sala-Trepat, Murray \& Williams, 1972) and genetic studies (Bayly \& Wigmore, 1973; Wigmore, Bayly \& Di Berardino, 1974). The regulation of enzymes of the meta-cleavage pathway has not been studied extensively. Feist \& Hegeman (1969) showed that phenol and the isomers of cresol are the functional inducers of the enzymes of the meta-cleavage pathway since non-metabolizable phenol analogues induced phenol hydroxylase and other enzymes of the pathway and phenol

* Present address: Department of Biochemistry, School of Medicine, University of Miami, Florida, U.S.A. 
Table I. Growth of wild-type strain and mutants with aromatic compounds as sole sources of carbon

Strains were inoculated on to solid basal medium and into liquid basal medium containing different carbon compounds $(2.5 \mathrm{~mm})$, and incubated at $30^{\circ} \mathrm{C}$ for $24 \mathrm{~h}$. Unless indicated otherwise, growth on both types of medium was the same.

\begin{tabular}{|c|c|c|c|c|c|}
\hline \multirow[b]{2}{*}{ Strain } & \multicolumn{5}{|c|}{ Carbon source } \\
\hline & Phenol & $o$-Cresol & $m$-Cresol & $p$-Cresol & Benzoate \\
\hline PsUo & + & + & + & + & + \\
\hline PsUDI $_{\text {S }}$ & $+*$ & - & - & - & + \\
\hline PsU07 & + & + & + & + & - \\
\hline $\mathrm{PsU}_{5} / \mathrm{RII}_{\mathrm{I}}$ & $+^{*}$ & - & - & - & + \\
\hline PsUL2 & + & + & - & - & + \\
\hline PsULI2 series & & & & & \\
\hline (solid) & + & + & + & - & + \\
\hline (liquid) & + & \pm & \pm & - & + \\
\hline
\end{tabular}

\footnotetext{
* Growth as a result of ortho-fission of catechol.

+ , Growth; -, no growth; \pm , growth after lag phase, which varied for different mutants of the PsULr 2 series.
}

induced the other enzymes in a phenol hydroxylase-defective mutant. Wigmore \& Bayly (1974) showed that it was probable that a single regulatory protein mediates the inductive control since, in a mutant strain with altered effector specificity, the expression of all enzymes of the meta-cleavage pathway was affected equally, suggesting that the metacleavage enzymes exist as a single regulon as defined by Maas \& Clark (1964). We now report evidence suggesting that this regulon is composed of two separately regulated operons.

\section{METHODS}

Media and growth conditions. The basal mineral salts medium of Hegeman (I966) was used with appropriate additions of sources of carbon. Phenol, catechol, or isomers of cresol were added at $2.5 \mathrm{~mm}$. Fumarate, benzoate, succinate, acetate and pyruvate were each added to give concentrations of $\mathrm{I} 0 \mathrm{~mm}$, unless otherwise specified. The final $\mathrm{pH}$ of the medium was $7 \cdot 4$. Solid media were prepared by the addition of $\mathrm{I} \cdot 2 \%(\mathrm{w} / \mathrm{v})$ Oxoid agar. Organisms were grown and suspensions and extracts were prepared as described by Bayly \& Wigmore (I973).

Isolation of mutants. The wild-type strain $P$. putida NCIBIOOI5 is designated PsUo. The growth substrate specificities of strain PsUo, and mutant strains derived from it, are listed in Table I. Mutants PsUDI and PsU5/RII, defective in catechol 2,3-oxygenase activity, have been described previously (Bayly \& Wigmore, 1973). Mutant PsUL2, previously reported by Wigmore \& Bayly (I974), has a regulatory element of altered specificity involved in the induction of meta-cleavage pathway enzymes. Mutant PsUo7 is blocked in the benzoate oxidase system which converts benzoate to catechol (Reiner, 197I); it was selected by the penicillin/D-cycloserine method as described by Wigmore $e$ t al. (1974). The selective carbon source (SCS) was catechol $(2.5 \mathrm{mM})$ and the contra-selective carbon source (CSCS) was benzoate $(2.5 \mathrm{~mm})$. After treatment with ethyl methanesulphonate (EMS) the bacteria were grown in basal medium plus fumarate before the first exposure to the CSCS. Mutants PsUli2, PsUlir, PsUli6, and PsULi 8 were selected by the same method except that the SCS was $m$-cresol $(2.5 \mathrm{mM})$ and the CSCS was $p$-cresol $(2.5 \mathrm{mM})$; these are referred to collectively as the PsULi2 series of mutants. Before EMS-mutagenized cells were first 
exposed to the CSCS they were grown on basal medium containing phenol. These mutants grew poorly on $m$-cresol and hence the enrichment must have been due solely to the bactericidal effects of the antibiotics in the presence of the CSCS, $p$-cresol. Mutants were lyophilized soon after isolation and maintained for use as described by Kemp \& Hegeman (I968).

Enzyme assays. The following enzymes were assayed by published procedures: catechol 2,3-oxygenase (EC I.I3.II.2), 2-hydroxymuconic semialdehyde hydrolase and NAD ${ }^{+}$dependent aldehyde dehydrogenase (Bayly \& Wigmore, 1973); 4-hydroxy-2-oxovalerate aldolase (Feist \& Hegeman, 1969) and 2-oxopent-4-enoate hydratase (Collinsworth, Chapman \& Dagley, 1973).

Oxygen uptake by washed suspensions. A Clark oxygen electrode (Rank Brothers, Bottisham, Cambridge) connected to a $10 \mathrm{mV}$ Speedomax recorder was used. The reaction vessel contained $290 \mu \mathrm{mol}$ phosphate buffer $\mathrm{pH} 7 \cdot 4$ saturated with air at $30^{\circ} \mathrm{C}$ and cell suspension in a total volume of $3 \mathrm{ml}$. After determination of endogenous uptake of oxygen, Ioo $\mu \mathrm{l}$ of substrate (Io $\mu \mathrm{mol} \mathrm{ml}^{-1}$ ) was added to the reaction vessel. At $30{ }^{\circ} \mathrm{C}$ the concentration of oxygen in the air-saturated buffer was taken to be $0.26 \mathrm{~mm}$.

Detection and estimation of catechol and 3- and 4-methylcatechols in culture supernatant fluids. To $2.9 \mathrm{ml}$ of sample (containing 3 to $50 \mathrm{nmol}$ catechol $\mathrm{ml}^{-1}$ and previously adjusted to $\mathrm{pH} 7 \cdot 6$ ) was added $\mathrm{O} \cdot \mathrm{I} \mathrm{ml}\left(2 \mathrm{mg}\right.$ protein) of heat-treated $\left(55^{\circ} \mathrm{C} ; 5 \mathrm{~min}\right)$ extract of phenolgrown cells of strain PsUo. When the reaction was complete, the absorption spectrum of the products of ring-cleavage of the catechol was determined, and the catechol derivative in the sample was identified and its concentration was determined using the spectral data of Bayly et al. (1966).

Estimation of protein. Protein in extracts was estimated by the method of Lowry et al. (I95I), using bovine serum albumin as standard.

Reagents. Catechol and 3- and 4-methylcatechols were obtained from Aldrich Chemical Co., Milwaukee, Wisconsin, U.S.A., and were purified by vacuum sublimation. Other reagents were obtained from commercial sources and used without further treatment.

\section{RESULTS}

Phenol hydroxylase and catechol 2,3-oxygenase in strain PsUo

Induction of phenol hydroxylase and catechol 2,3-oxygenase by phenol, catechol or isomers of cresol was studied in strain PsUo growing on either fumarate, acetate, pyruvate or succinate as carbon source. Synthesis of the enzymes was non-coordinate (Fig. I). After growth in the presence of catechol, no phenol hydroxylase activity was detected although significant levels of catechol 2,3-oxygenase were induced. The cresols tended to induce a lower ratio of phenol hydroxylase to catechol 2,3-oxygenase than did phenol.

Induction of both phenol hydroxylase and catechol 2,3-oxygenase was repressed by acetate. The repressive effect on phenol hydroxylase was greater than that on the oxygenase, especially at higher acetate concentrations (Table 2).

When strain PsUo growing in basal medium containing fumarate was exposed to a mixture of phenol and benzoate (2.5 mM), induction of catechol 2,3-oxygenase was unaffected but no phenol hydroxylase was detected. Growth was unaffected by adding benzoate, and substrate levels of benzoate $\left(300 \mathrm{nmol} \mathrm{ml}^{-1}\right)$ did not affect phenol hydroxylase activity in whole cells. The specific activity of catechol 2,3-oxygenase of strain PsUo grown in the presence of catechol was unchanged by the presence of $2.5 \mathrm{~mm}$-benzoate. Mutant PsU07 grew on phenol as a sole source of carbon with a doubling time of $90 \mathrm{~min}$ but was unable to 


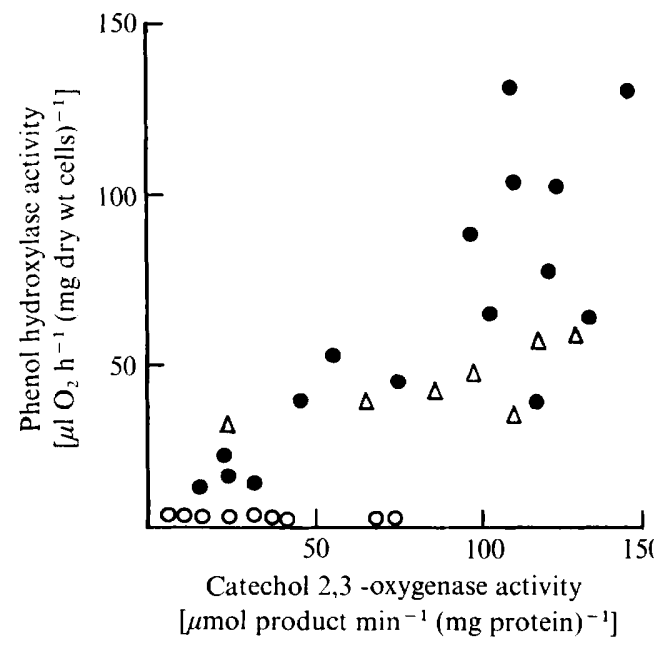

Fig. I. Induction of phenol hydroxylase and catechol 2,3-oxygenase by different inducers. To strain PsUo growing exponentially in basal medium containing fumarate (IO mM) was added either phenol $(\bigcirc)$, catechol $(\bigcirc)$, or $o-, m$ - or $p$-cresol $(\triangle)$ to a final concentration of $2.5 \mathrm{~mm}$. After $2 \mathrm{~h}$ further incubation, extracts were assayed for phenol hydroxylase and catechol 2,3-oxygenase activities as described in Methods. In some experiments, succinate (IO mM) or acetate (IO mM) was used instead of fumarate.

\section{Table 2. Effect of acetate on induction of phenol hydroxylase and catechol 2,3-oxygenase}

Strain PsUo was grown to mid-exponential phase in basal medium containing 5 mm-acetate and then phenol (2.5 mM) and various amounts of acetate were added to each flask. After $2 \mathrm{~h}$ further incubation, enzyme activities in cell suspensions were assayed as described in Methods. Results are expressed as the percentage activity relative to the activities of phenol hydroxylase and catechol 2,3-oxygenase produced with $2 \cdot 5 \mathrm{~mm}$ added acetate [ 190 and $382 \mu \mathrm{IO}_{2} \mathrm{~h}^{-1}$ (mg dry wt) ${ }^{-1}$ respectively].

$\begin{array}{ccc}\begin{array}{c}\text { Acetate added } \\ (\mathrm{mM})\end{array} & \begin{array}{c}\text { Phenol hydroxylase } \\ \text { activity }\end{array} & \begin{array}{c}\text { Catechol 2,3-oxygenase } \\ \text { activity }\end{array} \\ 2 \cdot 5 & 100 & 100 \\ \text { 10 } & 46 & 83 \\ 20 & 23 & 46 \\ 50 & <2 & 4 \cdot 7\end{array}$

grow on benzoate (Io mM) plus phenol, thus demonstrating the physiological significance of the repression of phenol hydroxylase by benzoate. The wild-type strain grew on both media with doubling times of 73 and 75 min respectively.

\section{Repression by monomethylcatechols}

When either 3- or 4-methylcatechol (2.5 mM) was added with phenol to a culture of mutant PsUDi growing on fumarate, phenol hydroxylase was repressed to approximately $50 \%$ of the level when phenol was added alone. The addition of 3 - or 4 -methylcatechol at $0.1 \mathrm{~mm}$ did not repress phenol hydroxylase but at I $\mathrm{mm}$ these monomethylcatechols repressed phenol hydroxylase by approximately $25 \%$. Growth of the culture was unaffected by the addition of either of the monomethylcatechols.

The effect of the monomethylcatechols on induction of catechol 2,3-oxygenase could not be tested in mutant PsUDI which is defective in this enzyme. However, they did not repress 
2-hydroxymuconic semialdehyde hydrolase, aldehyde dehydrogenase or 2-oxopent-4enoate hydratase, all enzymes acting later in the meta-cleavage degradation of phenol.

\section{Genetic evidence for non-coordinate expression of phenol hydroxylase and catechol 2,3-oxygenase}

The four mutants of the PsULi2 series, when tested by replica plating, were able to grow on all of the phenolic compounds tested except $p$-cresol. After the replica plates containing $p$-cresol had been incubated overnight, each mutant produced an orange-brown coloration of the medium at the site of inoculation; the appearance was identical to that of mutant PsUDI and the extragenically suppressed revertant PsU5/RI I (both defective in catechol 2,3-oxygenase) when these mutants were grown in the presence of $p$-cresol. This suggests either that mutants of the PsULi 2 series lack catechol 2,3-oxygenase activity when grown in the presence of $p$-cresol or that any catechol 2,3-oxygenase present is unable to use 4-methylcatechol as substrate.

All four mutants in the PsULr 2 series accumulated coloured products during growth in the presence of the isomers of cresol. After $4 \mathrm{~h}$ incubation in fumarate basal medium containing any isomer of cresol, the medium was blue-grey, and by $6 \mathrm{~h}$ it was red-purple. All these mutants grew at the same rate as the wild type in the presence of each phenolic compound when fumarate was present and also when phenol was the sole carbon source. Mutants PsULi2 and PsULi4 showed no growth after I5 h incubation when either $o$ - or $m$-cresol was the sole carbon source, but grew after $24 \mathrm{~h}$ incubation. Mutants PsULr6 and PsULi 8 grew at the expense of either $o$ - or $m$-cresol after a 9 to $10 \mathrm{~h} \mathrm{lag,} \mathrm{whereas} \mathrm{the} \mathrm{wild}$ type grew after a 4 to $5 \mathrm{~h}$ lag.

The coloured products accumulated during the growth of mutants of the PsULi2 series in liquid media in the presence of the isomers of cresol may be a consequence of the accumulation of monomethylcatechols. Catechol forms a blue complex with metallic ions, especially iron (Wheelis \& Stanier, I970), and the colour change to orange-brown may be due to quinone formation (Ribbons, 1970). Patel \& Gibson (1974) identified I,2-naphthoquinone as a non-enzymic autoxidation product of 1,2-dihydroxynaphthalene. Catechol could not be detected after growth of mutants of the PsULi2 series in the presence of phenol. The levels of monomethylcatechols accumulated were less than $10 \%$ of the level accumulated by mutant PsUDi (defective in catechol 2,3-oxygenase) under the same growth conditions.

The accumulation of monomethylcatechols during growth in the presence of the isomers of cresol indicates that the genetic defect in mutants of the PSULI2 series must be exerted at the level of catechol 2,3-oxygenase expression or function. The effect, as well as being conditional in that different behaviour was observed after growth on solid media and in liquid media containing either $o$ - or $m$-cresol (Table I), must also involve either substrate or effector specificity, depending on whether the altered gene determined either the catechol 2,3-oxygenase protein or a regulatory determinant respectively. The substrate specificity of the catechol 2,3-oxygenase induced by phenol in strain PsUo and mutant PsULI2 was unchanged as the ratio of enzymic activities determined with catechol or 3- or 4-methylcatechol as substrate was identical in the two strains.

However, in all mutants of series PsULi 2 , induction for $2 \mathrm{~h}$ with either $o$ - or $m$-cresol resulted in an 80 to $90 \%$ reduction of the specific enzymic activity compared with the wildtype strain and when $p$-cresol was used as inducer the reduction was 95 to $97 \%$ (Table 3 ). The percentage reduction in specific enzymic activity was independent of the substrate used for assay. The observations suggest that the behaviour of mutants of the PsULI 2 series is a 
Table 3. Specific activity of catechol 2,3-oxygenase in extracts of PsUo and mutants of the PsULi 2 series after induction with isomers of cresol $(2.5 \mathrm{mM})$ during growth on basal medium containing fumarate (Io $\mathrm{mM}$ )

Activities are expressed as $\mathrm{nmol} \mathrm{min}^{-1}(\mathrm{mg} \text { protein })^{-1}$.

\begin{tabular}{|c|c|c|c|c|c|c|}
\hline \multirow[b]{2}{*}{ Inducer } & \multirow[b]{2}{*}{ Substrate } & \multicolumn{5}{|c|}{ Strain } \\
\hline & & PsUo & PsULi2 & PsULI4 & PsULi6 & PsULi 8 \\
\hline \multirow[t]{3}{*}{$o$-Cresol } & Catechol & 90 & 20 & IO & 20 & IO \\
\hline & 3-Methylcatechol & IIO & 20 & 10 & 20 & 10 \\
\hline & 4-Methylcatechol & 410 & 80 & 50 & 90 & 40 \\
\hline \multirow[t]{3}{*}{$m$-Cresol } & Catechol & 120 & 30 & 20 & 30 & 20 \\
\hline & 3-Methylcatechol & I IO & 20 & 20 & 20 & 10 \\
\hline & 4-Methylcatechol & 390 & 120 & 70 & 120 & 60 \\
\hline \multirow[t]{3}{*}{$p$-Cresol } & Catechol & 60 & 3 & 4 & 3 & 3 \\
\hline & 3-Methylcatechol & 60 & 2 & 2 & 2 & 2 \\
\hline & 4-Methylcatechol & 160 & 9 & 10 & 6 & 6 \\
\hline
\end{tabular}

Table 4. Oxidation of phenol by suspensions of intact cells of strain PsUo and mutants of the PsULI2 series after induction with isomers of cresol $(2.5 \mathrm{mM})$ during growth on basal medium containing fumarate (IO mM)

Rates of oxidation are expressed as $\mu \mathrm{l} \mathrm{O}_{2} \mathrm{~h}^{-1}\left(\mathrm{mg}\right.$ dry wt) ${ }^{-1}$.

\begin{tabular}{lccccc} 
& \multicolumn{5}{c}{ Strain } \\
\cline { 2 - 6 } Inducer & PsUo & PsULi2 & PsULi4 & PsULi6 & PsULi 8 \\
$o$-Cresol & 56 & 56 & 36 & 42 & 24 \\
$m$-Cresol & 70 & 65 & 57 & 73 & 35 \\
$p$-Cresol & 46 & 17 & 12 & I I & I4
\end{tabular}

consequence of an altered effector specificity which results in reduced levels of catechol 2,3-oxygenase after induction with any of the isomers of cresol.

The low induced levels of catechol 2,3-oxygenase in mutants of PsULi2 series (Table 3) were consistent with the small amounts of monomethylcatechols that they accumulated compared with the amounts accumulated by mutant PsUDI, which lacked detectable catechol 2,3-oxygenase activity (Bayly \& Wigmore, 1973).

Wigmore et al. (1974) demonstrated coordinately lowered phenol hydroxylase and catechol 2,3-oxygenase activities when the mutant PsUL2 was induced with either $m$ - or $p$-cresol. The activities were about $10 \%$ and $\mathrm{I} \%$ of wild-type levels after induction with $\mathrm{m}$ and p-cresol respectively. Growth of mutant PsUL2 in the presence of any isomer of cresol as carbon source did not result in accumulation of either 3- or 4-methylcatechol under the conditions of growth tested, suggesting that in mutants of the PsULi 2 series there was also a non-coordinate lowering of phenol hydroxylase and catechol 2,3-oxygenase activities.

Phenol hydroxylase activity of each of the mutants of the PsULi2 series was determined after induction by isomers of cresol (Table 4). Although the rates of oxygen uptake were reduced when mutant PsULi 8 was induced with either $o$ - or $m$-cresol, mutants PsULi2, PsULI4 and PsULr6 had phenol hydroxylase activities similar to the wild type after induction by $o$ - or $m$-cresol. After induction by $p$-cresol, the phenol hydroxylase activities of all mutants of the PsULi2 series was about 30 to $40 \%$ of the wild-type level (Table 4 ) while catechol 2,3-oxygenase activities were reduced to about $5 \%$ of the wild-type level (Table 3). 
Table 5. Repression of some meta-cleavage pathway enzymes by acetate

Strain PsUo was grown to mid-exponential phase in basal medium containing 5 mm-acetate and then phenol (2.5 mM) and various amounts of acetate were added to each flask. After $2 \mathrm{~h}$ further incubation, enzyme activities in extracts were assayed as described in Methods. Results are expressed as the percentage repression of enzymic activity taking the value at $2.5 \mathrm{~mm}$ added acetate as zero repression.

$\begin{array}{ccccc}\begin{array}{c}\text { Acetate added } \\ (\mathrm{mM})\end{array} & \begin{array}{c}\text { Catechol } \\ \text { 2,3-0xygenase }\end{array} & \text { Hydrolase } & \begin{array}{c}\text { Hydrolase }+ \\ \text { Dehydrogenase }\end{array} & \text { Hydratase } \\ \text { I0 } & \text { I4 } & \text { I } 8 & 15 & 25 \\ 20 & 54 & 50 & 27 & 7 \mathrm{I} \\ 50 & 92 & 88 & 91 & 97\end{array}$

Thus the mutants of the PsULi2 series apparently have an altered regulatory element resulting in the differential effects on the expression of the phenol hydroxylase and catechol 2,3-oxygenase genes.

Catechol 2,3-oxygenase and subsequent enzymes are part of a single regulatory element

Benzoate and the monomethylcatechols repressed phenol hydroxylase in strain PsUo and mutant PsUDi respectively but did not repress other enzymes of the meta-cleavage pathway. Various concentrations of acetate added with the inducer repressed, probably coordinately, all the enzymes assayed (Table 5).

\section{DISCUSSION}

Biochemical studies of the wild-type strain PsUo and derived mutants suggest that the phenol hydroxylase gene is part of a different operon from that containing the genes determining the other enzymes of the meta-cleavage pathway.

The observation that catechol induced significant levels of enzymes of the meta-cleavage pathway in strain PsUo is consistent with the observations of Bayly (1969) and Murray \& Williams (1974), but different from that of Feist \& Hegeman (I969). Despite numerous attempts, induction of phenol hydroxylase by catechol has not been demonstrated for strain PsUo grown in batch culture with fumarate as sole carbon source. This is in contrast to the detection, by Murray \& Williams (1974), of phenol hydroxylase in catechol-grown organisms of the same strain. This discrepancy may be due to the concentration of catechol present during induction since significant levels of phenol hydroxylase have been observed in wild-type and mutant derivatives of strain PsUo grown in continuous culture in fumarate basal medium containing $2.5 \mathrm{~mm}$-catechol (D. I. McKenzie, unpublished observations), whereas the initial concentration present in batch culture would be reduced during growth of the culture.

Under all conditions of induction of strain PsUo so far tested, including induction with catechol, catechol 2,3-oxygenase and all subsequent enzymes of the meta-cleavage pathway appear to be expressed coordinately (Bayly \& Sexton, unpublished observations) and hence the genes coding for them may exist as part of a single operon. High acetate concentrations coordinately repressed catechol 2,3-oxygenase and subsequent enzymes. During growth of conditional catechol 2,3-oxygenase-constitutive derivatives of strain PsUo on solid media with various non-aromatic compounds as carbon source, catechol 2,3-oxygenase and subsequent enzymes were synthesized but phenol hydroxylase was not formed (Wigmore, Di Berardino \& Bayly, 1977). Studies of a polarity mutant, PsU5, described by Bayly \& Wigmore (I973), indicate that the genes coding for all enzymes required for the meta- 
bolism of 2-hydroxymuconic semialdehyde to acetaldehyde and pyruvate are contiguous and are transcribed as a polycistronic message (Wigmore \& Bayly, 1977). It is assumed that the 2,3-oxygenase gene transcript is part of this polycistronic message and that it must be located at the operator-proximal end (Wigmore \& Bayly, 1977).

Hence the genes determining the enzymes for the catabolism of phenol and the isomers of cresol in strain PsUo exist as two operons. One operon specifies only phenol hydroxylase whereas the second codes for catechol 2,3-oxygenase and all subsequent enzymes of the meta-cleavage pathway. It is highly probable that the operons constitute a single regulon. The phenolic substrate apparently serves directly as the effector molecule for the induction of all meta-cleavage pathway enzymes, as strains defective in phenol hydroxylase due to a structural gene mutation form wild-type levels of all other enzymes of the pathway when induced with phenol or an isomer of cresol (Feist \& Hegeman, 1969; Sala-Trepat et al., 1972; Wigmore, 1975). Studies of induction of the meta-cleavage pathway with nonmetabolizable phenol analogues also support this view (Feist \& Hegeman, 1969). The influence of the effector molecule is thought to be mediated by a single regulatory protein. In mutant strain PsUL2, the effector specificity of this regulatory protein has been altered so that $10 \%$ or $\mathrm{I}$ to $2 \%$ of wild-type levels of all meta-cleavage pathway enzymes are induced by $m$-cresol or $p$-cresol respectively (Wigmore \& Bayly, 1974).

Mutants of the PsULi2 series exhibit a conditional effect in that different behaviour was observed after growth on solid media and in liquid media containing either $o$ - or $m$-cresol. As yet we have no explanation of this phenomenon although the effect could be mediated by the regulatory protein. Similar behaviour was observed in conditional constitutive producers of catechol 2,3-oxygenase (Wigmore et al., 1977) and Bayly (1969) demonstrated the influence of growth conditions on the induction of both catechol I,2-oxygenase and catechol 2,3-oxygenase in strain PsUo.

The work was supported in part by grant no. D67/16545 from the Australian Research Grants Commission. D. McKenzie was the holder of a postgraduate fellowship from General Motors Holden. We wish to thank D. Di Berardino for skilled technical assistance and M. Barbour for useful discussions.

\section{REFERENCES}

BAYLY, R. C. (1969). The degradation of cresols by species of Pseudomonas. Ph.D. thesis, Monash University, Australia.

BAYLY, R. C. \& DAGLEY, S. (I969). Oxoenoic acids as metabolites in the bacterial degradation of catechols. Biochemical Journal III, 303-307.

BAYLY, R. C. \& WIGMORE, G. J. (1973). Metabolism of phenol and cresols by mutants of Pseudomonas putida. Journal of Bacteriology II3, II I 2-I I 20.

Bayly, R. C., Dagley, S. \& Gibson, D. T. (1966). The metabolism of cresols by species of Pseudomonas. Biochemical Journal ror, 293-30I.

Collinsworth, W. L., Chapman, P. J. \& Dagley, S. (1973). Stereospecific enzymes in the degradation of aromatic compounds by Pseudomonas putida. Journal of Bacteriology I13, 922-931.

DAGLEY, S. (1972). Microbial degradation of stable chemical structures: general features of metabolic pathways. In Degradation of Synthetic Organic Molecules in the Biosphere, pp. I-I6. Washington, D.C.: National Academy of Sciences.

Feist, C. F. \& Hegeman, G. D. (I969). Phenol and benzoate metabolism by Pseudomonas putida: regulation of tangential pathways. Journal of Bacteriology roo, 869-877.

Hegeman, G. D. (1966). Synthesis of the enzymes of the mandelate pathway by Pseudomonas putida. I. Synthesis of enzymes of the wild-type. Journal of Bacteriology 9I, I I $40-1$ I54.

Kemp, M. B. \& Hegeman, G. D. (I968). Genetic control of the $\beta$-ketoadipate pathway in Pseudomonas aeruginosa. Journal of Bacteriology 96, I488-1499. 
Lowry, O. H., Rosebrough, N. J., Farr, A. L. \& Randall, R. J. (I95I). Protein measurement with the Folin phenol reagent. Journal of Biological Chemistry 193, 265-275.

MAAS, W. K. \& ClaRK, A. J. (1964). Studies on the mechanism of repression of arginine biosynthesis. II. Dominance of repressibility in diploids. Journal of Molecular Biology 8, 365-370.

Murray, K. \& Williams, P. A. (I974). Role of catechol and the methylcatechols as inducers of aromatic metabolism in Pseudomonas putida. Journal of Bacteriology $\mathbf{1}$ 7, I I $53-\mathrm{I} 157$.

Patel, T. R. \& Gibson, D. T. (I974). Purification and properties of ( + )-cis-naphthalene dihydrodiol dehydrogenase of Pseudomonas putida. Journal of Bacteriology r r9, 879-888.

ReINER, A. M. (I97I). Metabolism of benzoic acid by bacteria: 3,5-cyclohexadiene-I,2-diol-1-carboxylic acid is an intermediate in the formation of catechol. Journal of Bacteriology ro8, 89-94.

Ribbons, D. W. (1970). Specificity of monohydric phenol oxidations by meta-cleavage pathways in Pseudomonas aeruginosa TI. Archiv für Mikrobiologie 74, I03-I I 5.

Sala-Trepat, J. M., Murray, K. \& Williams, P. A. (1972). The metabolic divergence in the meta-cleavage of catechols by Pseudomonas putida NCIB 10015 . Physiological significance and evolutionary implications. European Journal of Biochemistry 28, 347-356.

Stanier, R. Y., Palleroni, N. J. \& Doudoroff, M. (1966). The aerobic pseudomonads: a taxonomic study. Journal of General Microbiology 43, I 59-27I.

WheElis, M. L. (1975). The genetics of dissimilatory pathways in Pseudomonas. Annual Review of Microbiology 29, 505-524.

Wheelis, M. L. \& Stanier, R. Y. (1970). The genetic control of dissimilatory pathways in Pseudomonas putida. Genetics $66,245-266$.

Wigmore, G. J. (1975). Metabolism of phenol and cresols by mutant strains of Pseudomonas putida. Ph.D. thesis, Monash University, Australia.

Wigmore, G. J. \& BAyly, R. C. (1974). A mutant of Pseudomonas putida with altered regulation of the enzymes for degradation of phenol and cresols. Biochemical and Biophysical Research Communications 6o, 48-55.

Wigmore, G. J. \& BAYLY, R. C. (1977). A partial order for genes determining enzymes of the meta-cleavage pathway in Pseudomonas putida. Journal of General Microbiology 100, 65-69.

Wigmore, G. J., Bayly, R. C. \& Di Berardino, D. (1974). Pseudomonas putida mutants defective in the metabolism of the products of meta-fission of catechol and its methyl analogues. Journal of Bacteriology I20, 3 I-37.

Wigmore, G. J., Di Berardino, D. \& Bayly, R. C. (1977). Regulation of the enzymes of the meta-cleavage pathway of Pseudomonas putida: a regulatory model. Journal of General Microbiology 1oo, 81-87. 